\title{
Hidden Overconfidence and Advantageous Selection
}

\author{
Rachel J. Huang ${ }^{\mathrm{a}}$, Yu-Jane Liu ${ }^{\mathrm{b}}$ and Larry Y. Tzeng ${ }^{\mathrm{c}}$ \\ ${ }^{a}$ Graduate Institute of Finance, National Taiwan University of Science and Technology, \#43 Sec. 4, \\ Keelung Road, Taipei, 106, Taiwan. \\ E-mail: rachel@mail.ntust.edu.tw \\ ${ }^{\mathrm{b}}$ Department of Finance, Guanghua School, Peking University, 5, Yiheyan Rd Haidian District, \\ Beijing, 100871, China. \\ ${ }^{c}$ Department of Finance, National Taiwan University, 85, SEC 4, Roosevelt Rd, Taipei, 106, Taiwan.
}

Theories of adverse selection and moral hazard predict the occurrence of the risk and the coverage of the insurance should be positively correlated, whereas empirical researches find little support of it. This paper provides a theoretical model of hidden overconfidence and demonstrates that a competitive insurance market may settle on separating equilibrium with advantageous selection predicting a negative relationship between risk and coverage. By assuming heterogeneity in risk perception and hidden action on self-protection, we find that, in equilibrium, the rational type of individual takes precautions to reduce the loss probability, whereas the overconfident type of individual will not make any effort. In the separating equilibrium, the insurer provides a product with high coverage to attract rational type of individual (low risk), and a product with low coverage for overconfident type of individual (high risk). In addition, other types of equilibrium such as adverse selection or linear premium rate are also found.

The Geneva Risk and Insurance Review (2010) 35, 93-107. doi:10.1057/grir.2009.5; published online 23 March 2010

Keywords: insurance market; advantageous selection; asymmetric information; moral hazard; adverse selection; overconfidence

\section{Introduction}

It is well known that theories of adverse selection and moral hazard predict that the occurrence of risk and insurance coverage should be positively correlated. Rothschild and Stiglitz (1976) show that, under adverse selection, insurers provide a product menu to screen the insured so that high risks choose high coverage and low risks choose low coverage. On the other hand, the theory of moral hazard (such as Shavell, 1979) indicates that individuals with higher insurance coverage have less incentive to avoid risk. However, most recent empirical papers find that the occurrence of risk and insurance coverage 
are insignificantly positively correlated in automobile insurance (Richaudeau, 1999; Chiappori and Salanie, 2000) or even negatively correlated in life insurance (Cawley and Philipson, 1999), long-term care insurance (Finkelstein and McGarry, 2006), medigap insurance (Fang et al., 2008) and commercial fire insurance (Wang et al., 2009).

De Meza and Webb (2001) propose heterogeneous risk aversion to explain why most empirical studies cannot find consistent results as predicted by adverse selection or moral hazard. They assume that there are two types of individuals, the timid (risk-averse) type and the bold (risk-neutral) type. The insurer cannot observe the hidden risk preferences of the insured and provides a product menu to screen the insured. They show that the market equilibrium may settle where the timid type purchases insurance and invests in selfprotection to reduce the risk but the bold type neither purchases insurance nor invests in self-protection. The equilibrium is referred to as "advantageous selection". In this paper, we intend to show that the existence of advantageous selection could be explained by another rationale: hidden overconfidence. ${ }^{1}$

The presence of overconfidence is a phenomenon that has broad applications in psychology. ${ }^{2}$ Overconfidence stems from overestimation, being self-serving and being overoptimistic. De Bondt and Thaler (1995) state that overconfidence may be the most robust finding in the psychology of judgment. There is also an array of psychological evidence on managerial and investor behaviour in financial markets. For example, Ulrike and Geoffrey (2005) show that CEOs tend to overestimate the returns on investment projects. Barber and Odean (2001) find that overconfident investors engage in excessive trading, and men tend to be more overconfident than women when trading stocks.

Although overconfidence theory is becoming increasingly significant and influential in finance theories and the business world, there is little discussion on how overconfidence influences insurance decision making under asymmetric information. ${ }^{3}$ Recently, Sandroni and Squintani (2007) set up an

\footnotetext{
${ }^{1}$ Recently, researchers have proposed that the individual's hidden characteristics such as wealth (Liu and Browne, 2007), patience (Sonnenholzner and Wambach, 2009) and regret (Huang et al., 2007) could be other rationales for advantageous selection.

${ }^{2}$ Miller and Ross (1975) find evidence that people tend to attribute their success to their own ability. Alpert and Raiffa (1982) show that people tend to overestimate the precision of their predictions of uncertain events.

${ }^{3}$ In the absence of asymmetric information, researchers find that the degree of overconfidence (optimism) can shift the individual's insurance decision. For example, Leland (1980) demonstrates that investors who are more optimistic about the expectations regarding returns will purchase portfolio insurance. Cummins and Mahul (2003) conclude that an insured will demand less insurance coverage (a high deductible) when the individual is more optimistic regarding the insurer's insolvency risk.
} 
adverse selection model and assumed that some of the high risk-type individuals are overconfident to the extent that they believe that they are low-risk types. They show that compulsory insurance does not constitute a Pareto improvement in a society with a significant fraction of overconfident agents.

In this paper, we will investigate the competitive market equilibrium under hidden overconfidence. Specifically, the concept of overconfidence is defined as the overly optimistic estimation of the probability of good future events. Goel and Thakor (2002) model overconfident managers as being more willing to take risk because they perceive their situation to be less risky than it actually is. Our definition of overconfidence is consistent with that in Goel and Thakor (2002) and Sandroni and Squintani (2007) and can be characterized as optimism. It differs from the definition of overconfidence in the finance literature, such as in the studies by Daniel et al. (1998), Gervais and Odean (2001) and Gervais et al. (2005), which use the term "overconfident" to describe people who think that they have higher quality information than they really do. Furthermore, "hidden" overconfidence means that overconfidence is the individual's private information which the insurer cannot observe. For example, a driver who is very confident regarding his own driving skill could drive much faster than ordinary people. However, the insurer cannot figure out which driver is overconfident with regard to his or her driving ability.

We assume that, under a perfectly competitive insurance market ${ }^{4}$ there exist two types of insured who are heterogeneous only in terms of subjective loss probability. The rational type of individual's subjective loss probability is the same as the objective loss probability, whereas the overconfident type of individual subjectively believes that the loss probability is lower than the objective one. As individuals make decisions based on their subjective loss probability, we implicitly assume that the overconfident types of individual truly believe that they have relatively lower loss probabilities, and they do not realize that they are overconfident. Both types of individual can invest in selfprotection to reduce the loss probability. For simplicity, we further assume that the overconfident type of insured chooses not to expend effort. ${ }^{5}$ Thus, if the rational type of insured invests in self-protection, the loss probability of the rational type of insured becomes lower than that of the overconfident type of insured.

\footnotetext{
${ }^{4}$ Jeleva and Villeneuve (2004) focus on a monopoly insurance market and show that a pooling equilibrium may be optimal when the individuals make decisions based on their subjective belief, which is the private information of the insured. By setting a Bertrand competition in an oligopoly market, Koufopoulos (2002) discusses the market equilibrium by adopting the assumption that individuals are heterogeneous in terms of risk perception.

${ }^{5}$ In our model, those insured who are overconfident overestimate their loss probability but are not optimistic about their efforts.
} 
By adopting the Nash equilibrium concept, we find that the market equilibrium could settle where the loss probability and the insurance coverage are either negatively correlated or uncorrelated. We first show that hidden overconfidence could generate equilibrium with advantageous selection: the overconfident type of insured would not expend effort to reduce his/her loss probability and would purchase low coverage with a high premium rate, whereas the rational type of insured chooses to reduce loss probability and prefers high coverage with a low premium rate. Thus, our paper predicts that the occurrence of the loss and the coverage of the insurance could be negatively correlated, which provides theoretical support for the empirical findings of advantageous selection.

Second, we further show that the equilibrium could settle where both rational and overconfident individuals do not invest in self-protection. In this case, our paper predicts that the occurrence of the loss and the insurance coverage are uncorrelated. The finding in this equilibrium is consistent with empirical research that finds no significant relationship between risk and coverage. Furthermore, in this case, we find that both types of individuals are charged the same premium rate, which is consistent with Cawley and Philipson's (1999) finding that the difference in the premium rate for the high coverage and the low coverage is not significantly different from zero.

The remainder of this paper is organized as follows. The following section provides the model, the subsequent section discusses the market equilibrium and the final section concludes the paper.

\section{Model}

Our model is similar to de Meza and Webb's (2001) setting, which includes both hidden information and hidden action. Assume that all the individuals in the competitive insurance market have the same initial wealth $W$ and face a potential loss of size $L$. The individuals can choose to expend effort to reduce the loss probability. Without loss of generality, we assume that the individuals can either expend effort $f$ or make zero effort. ${ }^{6}$ The investment of selfprotection is a hidden action to the insurers.

Assume that individuals can be divided into two types according to their risk perception: the rational type $(R)$ and the overconfident type $(O)$. The ex ante objective probability of loss occurrence for both types is the same. Let $\pi_{j}, j=f, n$ denote the objective loss probability where the subscripts $f$ and $n$, respectively, represent the cases where the individuals expend effort $f$ and engage in no investment in self-protection. It is reasonable to assume that $\pi_{f}<\pi_{n}$.

\footnotetext{
${ }^{6}$ In this paper, we assume that $f$ is measured by utility.
} 
Furthermore, assume that the overconfident types subjectively believe that they have a lower loss probability. Without expending any effort, the subjective loss probability of a type $R(O)$ individual is equal to $\pi_{n}^{R}\left(\pi_{n}^{O}\right)$. Assume that $\pi_{n}=\pi_{n}^{R}>\pi_{n}^{O}$. After expending effort, the subjective loss probability of a type $R$ $(O)$ individual is equal to $\pi_{f}^{R}\left(\pi_{f}^{O}\right)$. Assume that $\pi_{f}=\pi_{f}^{R}>\pi_{f}^{O}$ and $\pi_{n}^{i}>\pi_{f}^{i}, i=R, O$. The subjective belief is the individual's private information.

The representative risk-neutral insurance company provides a menu of insurance contracts $(p, Q)$ to screen the individuals, where $Q$ and $p$, respectively, denote the insurance amount and the insurance premium rate, where $0 \leqslant Q \leqslant L$. Note that the insurers will price the contract with objective probabilities and charge a proportional insurance loading $\lambda>0$.

Assume that the forms of the utility functions of both types of insured are the same and are strictly increasing and concave. For a given insurance contract $(p, Q)$, if the individuals expend no effort, then the expected utility $(E U)$ of the type $i$ insured is

$$
\begin{aligned}
E U_{n}^{i}(p, Q)= & \pi_{n}^{i} U(W-L+Q-p Q) \\
& +\left(1-\pi_{n}^{i}\right) U(W-p Q), \quad i=R, O .
\end{aligned}
$$

If the individuals expend effort $f$, then the expected utility of the type $i$ insured is

$$
\begin{aligned}
E U_{f}^{i}(p, Q)= & \pi_{f}^{i} U(W-L+Q-p Q) \\
& +\left(1-\pi_{f}^{i}\right) U(W-p Q)-f, \quad i=R, O .
\end{aligned}
$$

After purchasing the insurance contract $(p, Q)$, the individual will invest in self-protection if and only if the investment can increase his/her expected utility, that is,

$$
\begin{aligned}
\Delta^{i}= & E U_{f}^{i}(p, Q)-E U_{n}^{i}(p, Q) \\
= & \left(\pi_{f}^{i}-\pi_{n}^{i}\right)[U(W-L+Q-p Q)-U(W-p Q)] \\
& -f \geqslant 0, \quad i=R, O .
\end{aligned}
$$

For simplicity, let us assume that the overconfident type of insured will never choose to expend effort to reduce his or her loss probability, that is, $\Delta^{O}<0$.

In the following section, we use diagrams to illustrate the equilibrium. In all of the figures, the $x$-axis represents the insured's wealth at the no-loss state, $W_{x}$, whereas the $y$-axis denotes his or her wealth at the loss state, $W_{y}$. The insured's endowment $(W, W-L)$ is labelled by point $E$. The upward-sloping curve $J$ shows the value of $\left(W_{x}, W_{y}\right)$ such that $\Delta^{R}=0$. As shown in de Meza and Webb (2001), $J$ is convex if the insured exhibits decreasing absolute risk aversion. 
The indifference curve of the rational type of insured, $I^{R}$, is divided into two parts by $J$ : the upper region of $J$ indicates that the rational type of individual takes no precautions, and the lower region shows that he/she does take precautions. The slope of $I^{R}$ is

$$
\left.\frac{d W_{y}}{d W_{x}}\right|_{I^{R}}=-\frac{1-\pi_{j}^{R}}{\pi_{j}^{R}} \frac{U^{\prime}\left(W_{x}\right)}{U^{\prime}\left(W_{y}\right)}, \quad j=f, n .
$$

Note that $\left(1-\pi_{n}^{R}\right) / \pi_{n}^{R}<\left(1-\pi_{f}^{R}\right) / \pi_{f}^{R}$, because $\pi_{f}^{R}<\pi_{n}^{R}$. Thus, $I^{R}$ is kinked and flattens above $J$.

$I^{O}$ denotes the overconfident type of insured's indifference curve. Under the assumption that $\Delta^{O}<0, I^{O}$ is without any kink. The slope of $I^{O}$ is

$$
\left.\frac{d W_{y}}{d W_{x}}\right|_{I^{O}}=-\frac{1-\pi_{n}^{O}}{\pi_{n}^{O}} \frac{U^{\prime}\left(W_{x}\right)}{U^{\prime}\left(W_{y}\right)} .
$$

The single crossing property will hold if $\pi_{n}^{O}<\pi_{f}^{R}<\pi_{n}^{R}$. In this case, $I^{O}$ is steeper than $I^{R}$ at any point. However, the single crossing property will not hold if $\pi_{f}^{R}<\pi_{n}^{O}<\pi_{n}^{R}$.

Lines $P_{f}$ and $P_{n}$ denote the zero profit lines of the insurer based upon the objective loss probabilities $\pi_{f}$ and $\pi_{n}$, respectively. Thus, $p_{j}=(1+\lambda) \pi_{j}$ on Line $P_{j}, j=f, n$. Line $\bar{P}$ is the zero profit line under the pooling contract. Thus, $\bar{p}=(1+\lambda)\left(\theta \pi_{f}+(1-\theta) \pi_{n}\right)$, where $\theta$ is the proportion of the individual's effort expended in the overall population.

\section{Market equilibrium}

The Nash equilibrium is examined in this Section. The equilibrium concept we adopt is consistent with that in Rothschild and Stiglitz (1976) and de Meza and Webb (2001). As this paper aims at advantageous selection, we will focus on a separating equilibrium. ${ }^{7}$ There are four properties in a separating equilibrium. First, each type prefers the contract it chooses to the contracts chosen by other types (incentive compatibility). Second, all agents participate in the insurance market voluntarily (participation constraint). Therefore, if purchasing insurance will result in a higher expected utility, the individuals will be insured. On the other hand, the firms will not offer a contract which gives rise to a negative profit. Third, individuals will invest in self-protection if the investment can result in a higher expected utility (effort incentive). Finally, the

\footnotetext{
${ }^{7}$ The pooling equilibrium and the non-existence of equilibrium are not the focuses of this paper.
} Therefore, we do not provide a discussion of these issues. 
insurance company will offer contracts to maximize its profit (profit maximization).

To find the equilibrium by means of graphic analysis, some contracts need to be identified first. Let $I^{i^{*}}$ denote the optimal utility level of type $i, i=R, O$. Denote contract $A=\left(p_{n}, Q^{A}\right)\left(B=\left(p_{f}, Q^{B}\right)\right)$ as the contract that results in the maximum expected utility level for type $O$ (type $R$ ) individuals under pricing line $P_{n}\left(P_{f}\right)$. Thus, $E U_{n}^{O}\left(p_{n}, Q^{A}\right) \geqslant E U_{n}^{O}\left(p_{n}, Q\right)$, and $E U_{f}^{R}\left(p_{f}, Q^{B}\right) \geqslant E U_{f}^{R}\left(p_{f}, Q\right)$, $\forall Q$. Contract $C=\left(p_{f}, Q^{C}\right)$ denotes the intersection of lines $J$ and $P_{f}$, i.e., $E U_{f}^{R}$ $\left(p_{f}, Q^{C}\right)=E U_{n}^{R}\left(p_{f}, Q^{C}\right)$. Furthermore, let contracts $D=\left(p_{f}, Q^{D}\right)$ and $D^{\prime}=$ $\left(p_{f}, Q^{D^{\prime}}\right), Q^{D}>Q^{D^{\prime}}$, denote the intersections of $I^{O^{*}}$ and line $P_{f}$. Thus,

$$
E U_{n}^{O}\left(p_{n}, Q^{A}\right)=E U_{n}^{O}\left(p_{f}, Q^{D}\right)=E U_{n}^{O}\left(p_{f}, Q^{D^{\prime}}\right) .
$$

Let contract $G=\left(p^{G}, Q^{G}\right)$ denote the intersection of $I^{O^{*}}$ and curve $J$, that is, $E U_{n}^{O}\left(p_{n}, Q^{A}\right)=E U_{n}^{O}\left(p^{G}, Q^{G}\right)$ and $E U_{f}^{R}\left(p^{G}, Q^{G}\right)=E U_{n}^{R}\left(p^{G}, Q^{G}\right)$. Let contract $H=\left(p_{n}, Q^{H}\right)$ denote the contract that type $R$ individuals will choose when they are priced by $P_{n}$.

Now, let us focus on the case where the single crossing property holds, that is, $\pi_{n}^{O}<\pi_{f}^{R}<\pi_{n}^{R}$. The following proposition demonstrates the condition for advantageous selection:

Proposition 1 The market settles on an equilibrium with advantageous selection in the following cases:

1. If $E U_{f}^{R}\left(p_{f}, Q^{D}\right) \geqslant E U_{n}^{R}\left(p_{f}, Q^{D}\right)$ and $E U_{n}^{O}\left(p_{f}, Q^{D}\right) \geqslant E U_{n}^{O}\left(p_{f}, Q^{B}\right)$, then the market settles on a separating equilibrium where type $O$ will choose contract $A$ and type $R$ will choose contract $B$ as shown in Figure 1.

2. If $E U_{f}^{R}\left(p_{f}, Q^{D}\right) \geqslant E U_{n}^{R}\left(p_{f}, Q^{D}\right)$ and $E U_{n}^{O}\left(p_{f}, Q^{D}\right)<E U_{n}^{O}\left(p_{f}, Q^{B}\right)$, then the market settles on a separating equilibrium where type $O$ will choose contract $A$ and type $R$ will choose contract $D$ as shown in Figure 2.

3. Suppose $E U_{f}^{R}\left(p_{f}, Q^{D}\right)<E U_{n}^{R}\left(p_{f}, Q^{D}\right)$. If $E U_{f}^{R}\left(p^{G}, Q^{G}\right)>E U_{f}^{R}(\bar{p}, Q)$ and $E U_{f}^{R}\left(p^{G}, Q^{G}\right)>E U_{n}^{R}\left(p_{n}, Q\right), \forall Q$, as shown in Figure 3 , then there exists a partial pooling equilibrium where type $O$ will choose contract $A$ and type $R$ will choose contract $G$.

Proof: From the figures, it is obvious that all characteristics in equilibrium are satisfied except for the profit maximization property. Therefore, in this proof, we will show that insurance companies cannot benefit from any deviation. In Figure 1, which shows case 1, the only way to induce type $R$ to deviate from $B$ is to provide contracts located above $I^{R^{*}}$. However, none of the insurers will do so, since doing so will result in a negative profit.

Figure 2 illustrates case 2 . To interest type $R$, the potential contracts should lie in the region below $P_{f}$ and above $I^{R^{*}}$. Any contract located in this area will also 


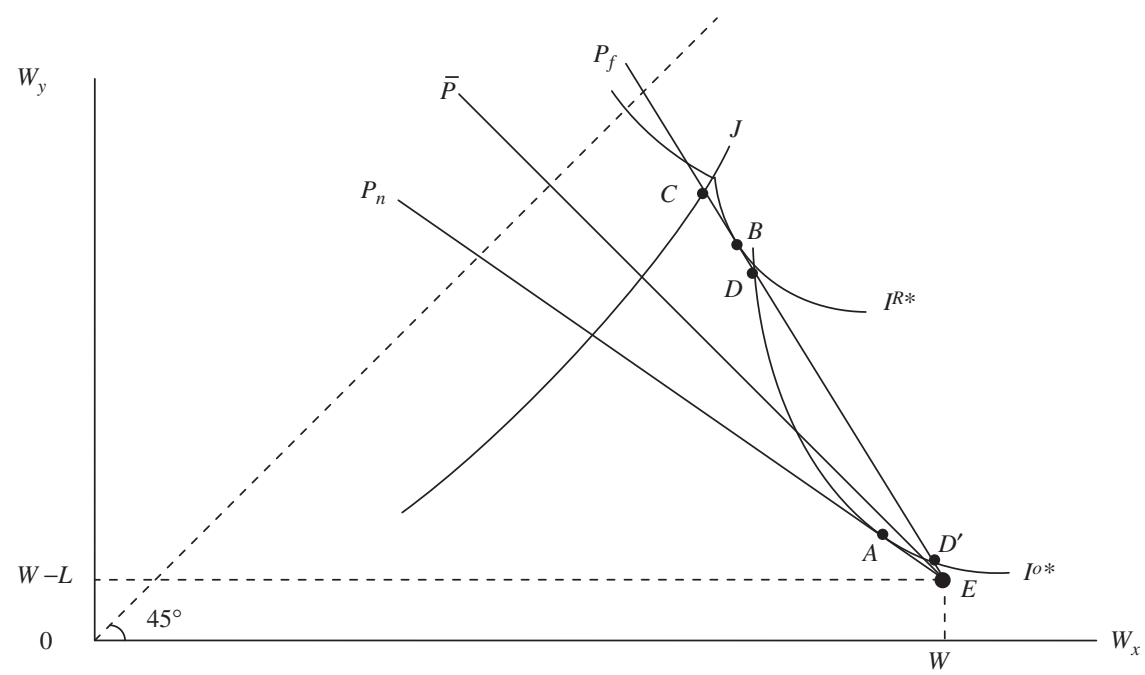

Figure 1. Separating equilibrium with advantageous selection (type $O$ prefers contract $D$ to $B$ ).

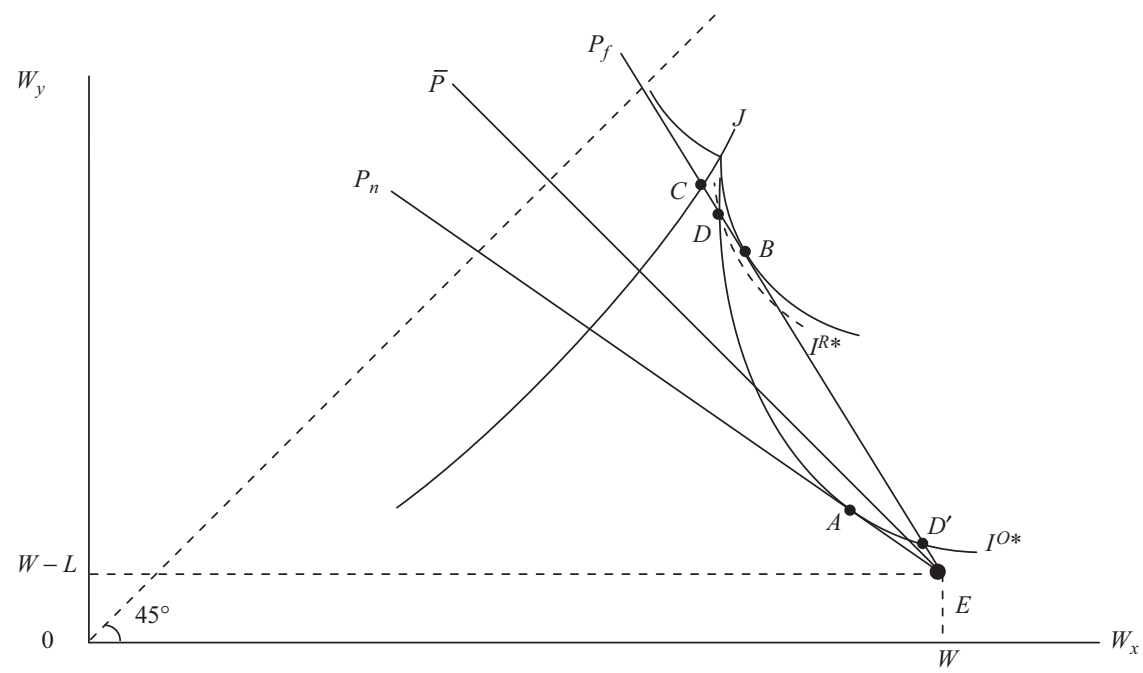

Figure 2. Separating equilibrium with advantageous selection (type $O$ prefers contract $B$ to $D$ ). 


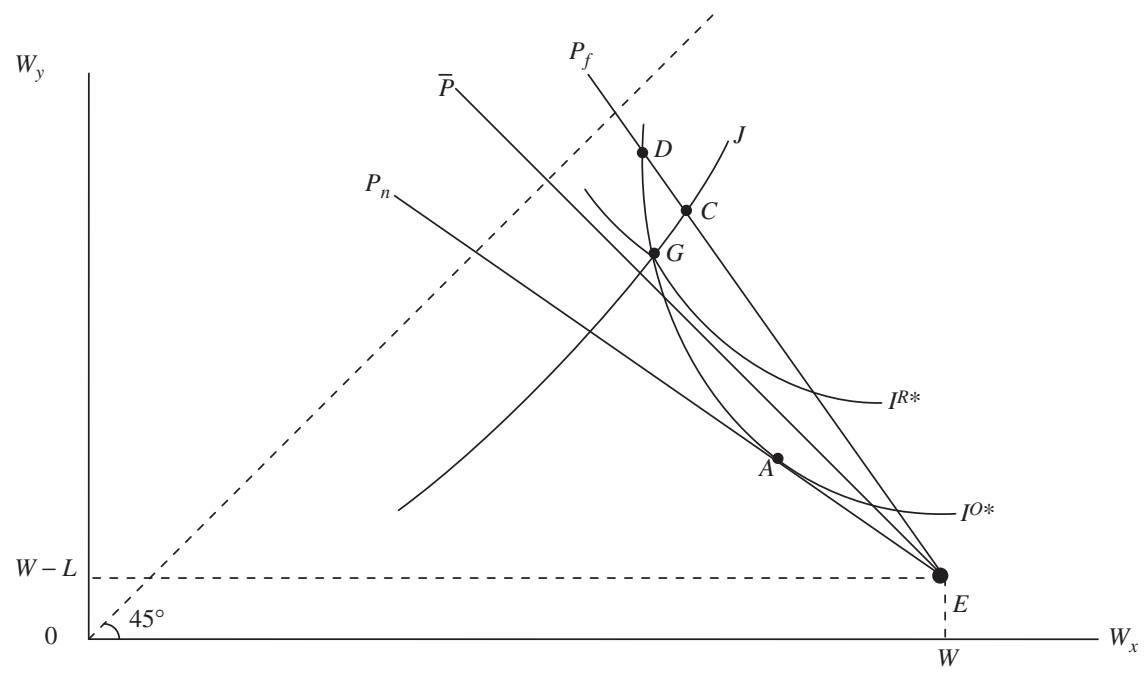

Figure 3. Partial pooling equilibrium.

captivate type $O$ individuals, and result in a pooling. However, this pooling contract lies above the zero profit line $\bar{P}$, which means that it is a negative profit strategy for insurers.

Figure 3 demonstrates case 3 . The possible profitable offer that could attract type $R$ individuals must be located below $P_{f}$ and above $I^{R^{*}}$. A contract located below $J$ and surrounded by $P_{f}$ and $I^{R^{*}}$ will ensure that the type $R$ individuals will take precautions and simultaneously improve the welfare of both types of insured. However, the insurer will lose money in this area, because the pooling pricing line $\bar{P}$ is located below this area. On the other hand, in the sub-region above $J$ and $I^{R^{*}}$, the rational type of insured refuses to make any effort, and leaves the market only one type of insured: the high-risk type. Thus, the insurer should at least ask for $P_{n}$ for all individuals to avoid a negative profit, which is a much higher premium rate than the insurer offers in this area.

Contrary to the findings in Rothschild and Stiglitz (1976), Proposition 1 shows that, in equilibrium, type $R$ individuals will invest in self-protection (low risk) and will purchases high coverage with a low premium rate, whereas type $O$ individuals will not invest in self-protection (high risk) and will purchase low coverage with a high premium rate. In other words, the market settles on advantageous selection. Proposition 1 indicates that overconfidence can be one of the rationales for advantageous selection.

In the first case of Proposition 1, the existence of the overconfident type of individual does not result in any negative externality for the rational type of 
102

individual. Complementing the finding of Sandroni and Squintani (2007), in this case the government cannot achieve a Pareto improvement by providing compulsory insurance even through the market does not have a significant fraction of overconfident agents.

In the second case of Proposition 1, the existence of type $O$ individuals gives rise to a negative externality on type $R$ individuals. In order to be separated from the overconfident type, the rational type of insured will purchase higher coverage than his/her optimal level $(B)$ while expending effort. The mechanism of this separating equilibrium is the same as that in Rothschild and Stiglitz (1976). The "bad" insured, who is the high risk type in Rothschild and Stiglitz's (1976) model and is the overconfident type in ours, could settle for his or her first best allocation, but the "good" type of insured, who is low risk type in their model and is rational type in ours, could only choose the contract where the "bad" insured feels indifferent regarding his or her first best allocation, because of the negative externality caused by the "bad" insured. In this case, our separating equilibrium has the same implications as the equilibrium in Proposition 2 of de Meza and Webb (2001).

The third case of Proposition 1 demonstrates that the insurers appear to have a chance to make a profit from the rational type of insured in a competitive market. Type $R$ individuals are willing to take precautions to reduce their loss probability in equilibrium. In order to screen the insured, the insurers can price the rational type of insured at a premium rate that is greater than what makes zero profit. This strategy favors the insurer. However, the market is under perfect competition, which means that no firms could generate a positive profit. Thus, in equilibrium, there must be some type $O$ individuals who choose contract $G$ as shown in Figure 3, and who consume all the profit that the insurer obtained from type $R$ individuals. This partial pooling equilibrium is consistent with Proposition 1 of de Meza and Webb (2001).

In addition to advantageous selection, we further find that the market could settle where both types would not invest in self-protection as shown in the next Proposition:

Proposition 2 If $E U_{n}^{R}\left(p_{f}, Q^{D}\right)>E U_{f}^{R}\left(p_{f}, Q^{D}\right), E U_{n}^{R}\left(p_{n}, Q^{H}\right)>E U_{f}^{R}\left(p_{f}, Q^{D^{\prime}}\right)$ and $E U_{n}^{R}\left(p_{n}, Q^{H}\right)>E U_{f}^{R}(\bar{p}, Q), \forall Q$, as shown in Figure 4, then type $O$ will choose contract $A$ and type $R$ will choose contract $H$ in equilibrium.

Proof: First of all, no insurance company would like to offer the other contract located in the upper region of curve $J$. This is because neither type will invest in self-protection for the contract in this area. On the other hand, if an insurance company offers a contract located in the region surrounded by curve $J, I^{R^{*}}$ and $P_{f}$, the contract will attract both types of individuals. Since the 


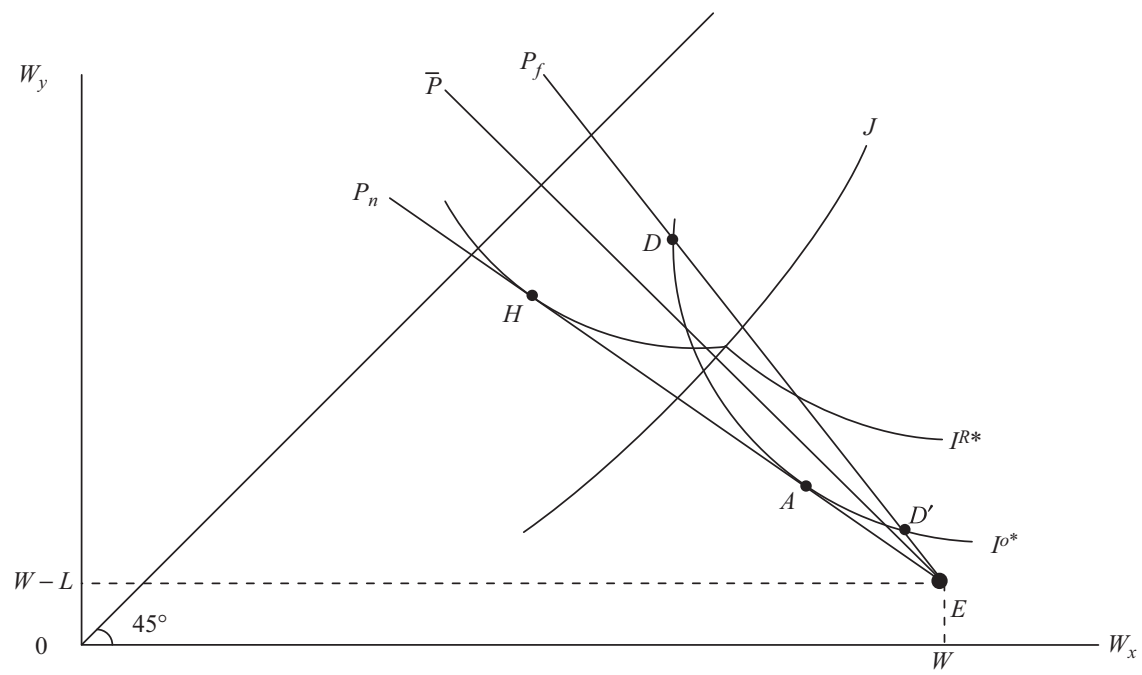

Figure 4. Separating equilibrium for a linear premium rate.

average pricing line is below this area, insurance companies cannot benefit from the deviation.

Proposition 2 shows the case where both types of insured choose not to make any effort in equilibrium. In this case, the market has only one risk type rather than two risk types. However, type $O$ individuals will purchase less insurance than type $R$ individuals since they are optimistic. This separating equilibrium does not separate risk type, but it does separate hidden overconfidence. In other words, the hidden overconfidence will be revealed by self-selection. Unlike adverse selection or advantageous selection, regardless of the level of coverage the insured chooses, both types of individuals have the same loss probability and are charged the same premium rate.

The empirical implications of this case differ from those of de Meza and Webb (2001) in two ways. First, it predicts that the conditional correlation between loss probability and the choice of coverage will be insignificantly different from zero, whereas de Meza and Webb (2001) predict a negative relationship. Second, it predicts that the premium rate and coverage could be insignificantly related, because the premium rate will be the same for all levels of coverage.

Furthermore, if the single crossing property does not hold, that is, $\pi_{f}^{R}<\pi_{n}^{O}<\pi_{n}^{R}$, then the market equilibrium may settle on adverse selection. As shown in Figure 5, when $E U_{n}^{R}\left(p_{f}, Q^{D}\right)>E U_{f}^{R}\left(p_{f}, Q^{D}\right), \quad E U_{f}^{R}\left(p_{f}\right.$, $\left.Q^{D^{\prime}}\right)>E U_{n}^{R}\left(p_{n}, Q\right)$ and $E U_{f}^{R}\left(p_{f}, Q^{D^{\prime}}\right)>E U_{f}^{R}(\bar{p}, Q), \forall Q$, the type $O$ will choose 
104

contract $A$ and type $R$ will choose contract $D^{\prime}$ in equilibrium, which represents adverse selection.

It is worth noting that the degree of overconfidence could be one of the key factors affecting the equilibrium. The shapes of all the curves in the figures will not be influenced by the change in the degree of overconfidence except in the case of the indifference curve of the overconfident type. If the degree of optimism of type $O$ individuals increases, then $I^{O}$ will become steeper since

$$
\frac{d\left(\left.\frac{d W_{y}}{d W_{x}}\right|_{I^{O}}\right)}{d \pi_{n}^{O}}=\frac{1}{\left[\pi_{n}^{O}\right]^{2}} \frac{U^{\prime}\left(W_{x}\right)}{U^{\prime}\left(W_{y}\right)}>0 .
$$

Therefore, when the type $O$ individuals become very optimistic such that they would choose a very low level of coverage, then contract $B$ with its high level of coverage and low premium rate may not be attractive to type $O$ individuals. This would be the first case in Proposition 1. When the degree of optimism decreases, the indifference curve of type $O$ individuals will become flatter, which implies that type $O$ individuals will demand higher levels of coverage. Therefore, there will be a greater chance that type $O$ individuals will prefer contract $B$ to contract $A$, and the second and third cases in Proposition 1 may be observed. If the degree of optimism of type $O$ individuals is less strong such that the type $O$ individuals always demand more coverage than the type $R$ individuals who decide to make efforts, then the market may settle on adverse

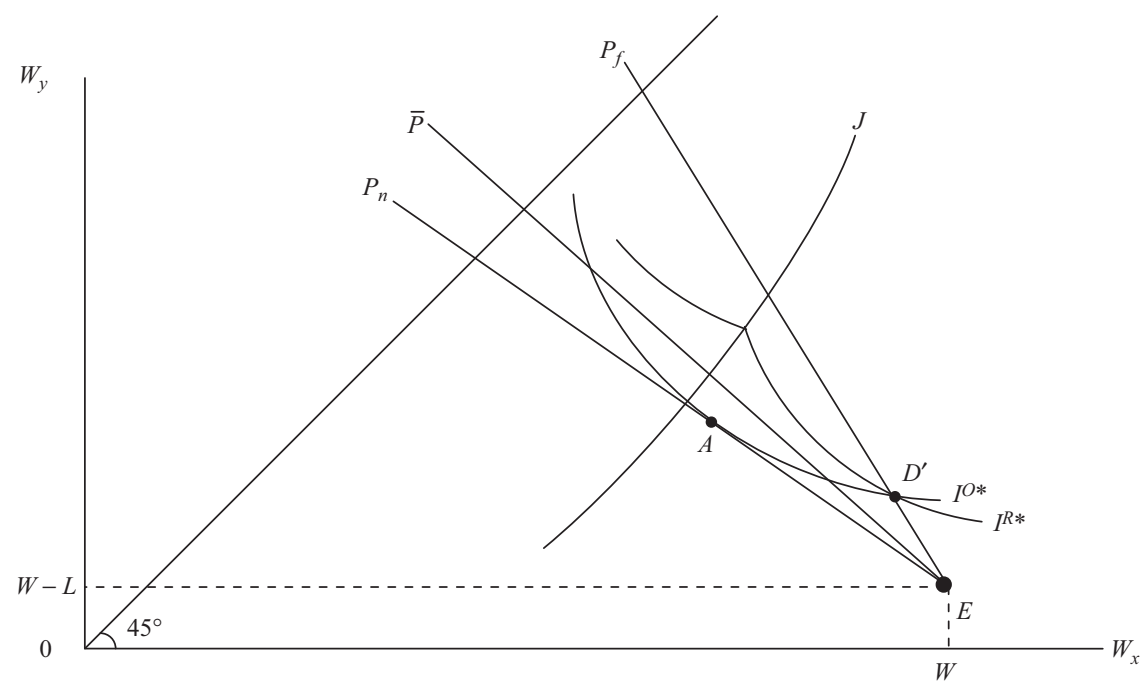

Figure 5. Adverse selection. 
selection. In summary, the different degrees of optimism of the type $O$ individuals give rise to different types of equilibrium.

\section{Conclusion}

Our paper has demonstrated that hidden overconfidence can lead the market toward advantageous selection. The market could settle where the rational type individuals purchase high coverage at a low premium rate, and at the same time take precautions to reduce their loss probability. Meanwhile, the overconfident types of individual will choose an insurance contract with low coverage and a high premium rate, and will refuse to expend effort. In addition, our paper also indicates that the market could settle on another separating equilibrium which does not separate risk type, but instead separate the degree of hidden overconfidence.

Both de Meza and Webb (2001) and our paper contribute to the literature by providing a rationale for the existence of advantageous selection. However, we focus on different empirical implications. Our paper can provide a theoretical background for the papers that find that individuals who are more subjectively optimistic regarding their loss probability are less likely to purchase insurance. Moreover, our paper can also provide explanations for several empirical papers that find no evidence of either adverse selection or advantageous selection.

Furthermore, for future empirical studies, our paper could provide different hypotheses from those provided by de Meza and Webb (2001). To test advantageous selection, the individual's risk preference and the individual's subjective beliefs regarding loss probability should be controlled. ${ }^{8}$

In addition, the term "overconfidence" is defined in different ways in the literature. In our paper, overconfidence is similar to optimism. For future theoretical studies, researchers could modify the definition of overconfidence in order to further investigate the market equilibrium.

An immediate application of our findings is that any proxy which can capture the overconfidence characteristic of the individuals could help the insurer to screen policyholders. Indeed, some of the variables related to overconfidence (such as gender and age) have been used by the insurer in underwriting. Recent literature has identified that overconfidence appears to have influence on investment management and wealth management. Our findings suggest that further employment of recently found variables

\footnotetext{
${ }^{8}$ In fact, both hidden risk preference and hidden overconfidence could co-exist in the market and
} jointly result in advantageous selection. 
related to overconfidence could help the improvement of underwriting performance.

\section{About the Authors}

Rachel J. Huang is Associate Professor at the Graduate Institute of Finance, National Taiwan University of Science and Technology, Taiwan.

Yu-Jane Liu is Professor at the Department of Finance, Guanghua School, Peking University, China.

Larry Y. Tzeng is Professor at the Department of Finance of National Taiwan University, Taiwan.

\section{Acknowledgements}

Yu-Jane Liu would like to thank CFSCFI for financial support grant no, 70873002. Larry Tzeng would like to thank the National Science Council for financial support (NSC96-2416-H-002-026MY3).

\section{References}

Alpert, M. and Raiffa, H. (1982) 'A progress report on the training of probability assessors', in D. Kahneman, P. Slovic and A. Tversky (eds) Judgement under Uncertainty: Heuristics and Biases, Cambridge: Cambridge University Press.

Barber, B.M. and Odean, T. (2001) 'Boys will be boys: Gender, overconfidence, and common stock investment', Quarterly Journal of Economics 116: 261-292.

Cawley, J. and Philipson, T.J. (1999) 'An empirical examination of information barriers to trade in insurance', American Economic Review 89(4): 827-846.

Chiappori, P.A. and Salanie, B. (2000) 'Testing for asymmetric information in insurance markets', Journal of Political Economy 108(1): 56-78.

Cummins, J.D. and Mahul, O. (2003) 'Optimal insurance with divergent beliefs about insurer total default risk', Journal of Risk and Uncertainty 27(2): 121-138.

Daniel, K., Hirshleifer, D. and Subrahmanyam, A. (1998) 'A theory of overconfidence, self-attribution, and security market under- and over-reactions', Journal of Finance 53(6): $1839-1885$.

De Bondt, W.F.M. and Thaler, R.H. (1995) 'Financial decision-making in markets and firms: A behavioral perspective', in R.A. Jarrow, V. Maksimovic and W.Z. Ziemba (eds) Finance, Handbooks in Operations Research and Management Science, Vol. 9, Amsterdam: North Holland, pp. 385-410.

De Meza, D. and Webb, D.C. (2001) 'Advantageous selection in insurance markets', Rand Journal of Economics 32(2): 249-262.

Fang, H., Keane, M. and Silverman, D. (2008) 'Sources of advantageous selection: Evidence from the Medigap insurance market', Journal of Political Economy 116(2): 303-350. 
Finkelstein, A. and McGarry, K. (2006) 'Multiple dimensions of private information: Evidence from the long-term care insurance market', American Economic Review 96(4): 938-958.

Gervais, S., Heaton, J.B. and Odean, T. (2005) Overconfidence, investment policy, and manager welfare, working paper.

Gervais, S. and Odean, T. (2001) 'Learning to be overconfident', The Review of Financial Studies 14(1): $1-27$.

Goel, A.M. and Thakor, A. (2002) Do overconfident managers make better leaders? working paper, University of Michigan.

Huang, R.J., Muermann, A. and Tzeng, L.Y. (2007) Hidden regret in insurance markets: Adverse and advantageous selection, working paper.

Jeleva, M. and Villeneuve, B. (2004) 'Insurance contracts with imprecise probabilities and adverse selection', Economic Theory 23(4): 777-794.

Koufopoulos, K. (2002) 'Asymmetric information, heterogeneity in risk perceptions and insurance: An explanation to a puzzle', University of Warwick, UK, mimeo.

Leland, H.E. (1980) 'Who should buy portfolio insurance?' Journal of Finance 35(2): 581-595.

Liu, J.W. and Browne, M.J. (2007) 'First-best equilibrium in insurance markets with transaction costs and heterogeneity', Journal of Risk \& Insurance 74(4): 739-760.

Miller, D.T. and Ross, M. (1975) 'Self-serving bias in attribution of causality: Fact or fiction?' Psychological Bulletin 82: 213-225.

Richaudeau, D. (1999) 'Automobile insurance contracts and risk of accident: An empirical test using French individual data', The Geneva Risk and Insurance Theory 24: 97-114.

Rothschild, M. and Stiglitz, J.E. (1976) 'Equilibrium in competitive insurance markets: An essay on the economics of imperfect information', Quarterly Journal of Economics 90(4): 629-649.

Sandroni, A. and Squintani, F. (2007) 'Overconfidence, insurance, and paternalism', American Economic Review 97(5): 1994-2004.

Shavell, S. (1979) 'On moral hazard and insurance', Quarterly Journal of Economics 93(4): 541-562.

Sonnenholzner, M. and Wambach, A. (2009) 'On the role of patience in an insurance market with asymmetric information', Journal of Risk and Insurance 76(2): 323-341.

Ulrike, M. and Geoffrey, T. (2005) 'CEO overconfidence and corporate investment', Journal of Finance 60(6): 2661-2700.

Wang, K., Huang, R.J. and Tzeng, L.Y. (2009) 'Empirical evidence for advantageous selection in the commercial fire insurance market', Geneva Risk and Insurance Review 34: 1-19. 